\title{
TYPE I CONGENITAL CYSTIC ADENOID MALFORMATION CAUSING RIGHT MEDIASTINAL SHIFT IN A TWO YEARS OLD CHILD
}

\author{
Mayuri A. Kamble ${ }^{1}$, Anand P. Thawait ${ }^{2}$, Ashok T. Kamble ${ }^{3}$
}

\section{HOW TO CITE THIS ARTICLE:}

Mayuri A. Kamble, Anand P. Thawait, Ashok T. Kamble. “Type I Congenital Cystic Adenoid Malformation Causing Right Mediastinal Shift in a Two Years Old Child". Journal of Evolution of Medical and Dental Sciences 2014; Vol. 3, Issue 28, July 14; Page: 7780-7786, DOI: 10.14260/jemds/2014/2971

ABSTRACT: Congenital cystic adenomatoid malformations (CCAM) of lung are rare, congenital, cystic, developmental hamartomatous malformation of lung, arising from excessive disorganized proliferation of tubular bronchial structures. Very few cases have been reported in literature. Although it is a disorder of infancy, majority of cases are being diagnosed within first two years of life. We describe CCAM in two years old girl who presented with recurrent lower respiratory tract infections, since infancy and had type I CCAM of upper and middle lobe causing mediastinal shift to right.

KEYWORDS: Congenital cystic adenoid malformation, type I, upper and middle lobe, mediastinal shift.

INTRODUCTION: Congenital cystic adenomatoid malformations (CCAM) are rare congenital lung developmental anomalies.[1] Though first reported by Ch'In and Tang in 1949, in premature children, Craig, Kirkpatrick, and Neuhauser reported first four surgically treated cases, in first two weeks of neonatal life, in 1956.[1] CCAM causing mediastinal shift and compression over heart has not been reported so far. The incidence of CCAM is one in 25,000 to 1 in 35,000 pregnancies with males and females equally affected. $90 \%$ of cases are diagnosed within first two years of life.[2]

An arrest in lung development between 4th and 7th week of fetal life produces bronchopulmonary foregut malformations and thus CCAM.[3] Histologically, CCAM are benign hamartomatous or dysplastic lung tumor, showing adenomatous overgrowth of terminal bronchioles with reduction in alveoli. Long term outcome is excellent in surgically treated patients.

CASE REPORT: Two years old female, presented with moderate to high grade, recurrent fever, off and on, non-productive cough and breathlessness while playing, since birth. The patient had history of repeated admissions in other hospitals with diagnosis of recurrent lower respiratory tract infection, every month since one year, for which she was treated with bronchodilators and antibiotics. There was only partial response to treatment. The baby had failure to thrive with loss of weight. There were no other complaints.

On admission, she was febrile, tachypnoic with pulse rate of $150 / \mathrm{min}$, regular, average flow, BP 90/60 mm Hg and respiratory rate of 40/min. Her weight was 9kgs. She was pale, anicteric with no cyanosis, clubbing or lymphadenopathy. Respiratory system examination revealed decreased breath sounds and decreased vocal resonance on left side along with decreased chest wall movement. There were occasional end expiratory crackles. The apex beat was shifted to right.

Laboratory investigations revealed microcytic hypochromic anemia with neutrophilic leukocytosis. Chest radiograph showed evidence of pleural effusion along with left upper and middle lobe consolidation and right mediastinal shift with heart compressed to right [Fig. 1]. Computed 
tomography (CT) of the thorax revealed multiple non enhancing fluid density cystic lesions largest of size $2.5 \times 2.3 \times 1.9 \mathrm{cms}$, with peripheral wall enhancement in apical and posterior segment of left upper lobe and apical and lateral basal and posterior basal segments of left lower lobe [Fig. 2].

Trachea, bilateral bronchi and heart was shifted to right. The radiological picture was suspicious of secondarily infected congenital cystic adenoid malformation of left lung with right mediastinal shift. Rest of the lung was normal.

The patient was planned for surgery. Left fifth intercoastal space posterolateral thoracotomy was performed. Intra-operatively, large non aerated lung was visualized involving upper and middle lobe with normally aerated but compressed lower lobe [Fig. 3]. The heart was pushed to right. A line of demarcation was visualized with inflation of lung. A plane was created between functioning and non-functioning lung, and then the non-functioning lung was resected. Hemostasis was achieved and small air leak was controlled with 3-0 silk. During excision, multiple pus filled cysts were observed [Fig 4].

Post excision, the heart occupied its normal position and the expansion of normal lower lobe of lung was seen [Fig. 5]. The thorax was closed in layers with under water seal drain. On gross examination, the resected specimen measured $7.5 \times 5 \times 2.5 \mathrm{cms}$ [Fig. 6]. External surface was well circumscribed, grayish white. Cut surface showed presence of cystic dilated spaces, filled with pus and hemorrhage. Histopathological examination showed congenital cystic adenomatoid malformation of lung.

The post-operative course was uneventful. The ICD was removed on $5^{\text {th }}$ postoperative day. Repeat chest X-ray showed inflation of lower lobe of left lung with shift of heart to left [Fig 7]. On auscultation, the air entry was same as compared to opposite side with apex beat shifted to left.

DISCUSSION: Congenital cystic adenomatoid malformation is an uncommon congenital malformation of lung, arising from excessive disorganized proliferation of terminal, tubular bronchial structures excluding alveoli. CCAM represents focal pulmonary dysplasia as confirmed by identification of skeletal muscle within cyst wall.[4]

Embryologically, based on anatomical changes occurring in lung, vertebrate lung development has been subdivided into five distinct periods: embryonic (3-7 weeks), pseudoglandular (7-17 weeks), canalicular (17-29 weeks), saccular (24-36 weeks), and alveolar (36 weeks to maturity). The CCAM develops during pseudoglandular and saccular period (7-35weeks).[4]

The incidence of CCAM is one in 25,000 to 1 in 35,000 pregnancies with males and females equally affected. CCAM constitutes $25 \%$ of all congenital lung lesions. Left and right lung are equally affected and single lobe disease is four times more common than multilobe disease. ${ }^{[5]}$

The most common mode of presentation is acute respiratory distress, in neonatal period, secondary to cyst expansion and compression of surrounding structures. Cyst expansion occurs through ball-valve mechanism causing air trapping. Mediastinal shift to opposite side secondary to CCAM has not been reported so far. Patient may remain asymptomatic till discovered in latter life on routine chest $X$-ray or may present, after neonatal period, as recurrent pneumonia, as in our case.[6]

Secondary bacterial, mycotic or tubercular infection of congenital cysts may produce lung abscess or pneumatocele with loculated pleural effusion. ${ }^{[7]}$

Stocker et al (1977) ${ }^{[8]}$ described three different types of CCAM. Type I (50\% of cases) consists of irregular, large, cystic mass $(2-10 \mathrm{cms})$ with smaller cysts interspersed in between. The cysts are 


\section{CASE REPORT}

lined by pseudostratified columnar ciliated epithelium, overlying a relatively prominent fibro muscular layer and occasionally produce mucin.

Type II ( $40 \%$ of cases) consists of numerous small cysts $(0.5 \mathrm{~cm}$ to $2 \mathrm{cms})$, lined by cuboidal or columnar epithelium, with thin-walled bronchiole like structures and without a predominant large cyst component. Type III (10\% of cases) consists of innumerable, evenly distributed, small adenomatoid cysts, measuring less than $0.2 \mathrm{~cm}$.

The lesion may occupy entire lobe or most of one lung. Microscopically, immature lung with predominant alveoli-like structures, lined by cuboidal cells, are seen.[9] Type II CCAM is usually associated with other congenital anomalies like renal agenesis, potter's syndrome, pulmonary hypoplasia, anasarca, pectus excavatum, cardiac anomalies and bile duct hypoplasia. Stocker recently added two more types to existing classification of CCAM and termed it congenital pulmonary airway malformation (CPAM).[10]

The differential diagnosis includes pleuropulmonary blastoma (PPB), pulmonary sequestration, congenital lobar emphysema, diaphragmatic hernia, bronchogenic cyst and cystic bronchiectasis. ${ }^{[11]}$ Radiographically, PPB shows either intra-cystic mass or septal thickening, same as CCAM. However, CCAM shows only cysts lined by respiratory epithelium, with muscle and fibrous tissue, within cyst wall and absence of malignant cells, cambium layer and any blastemal or sarcomatous component, as seen in pleuropulmonary blastoma. On immunohistochemistry, the rhabdomyoblastic component of PPB stain positive for myogenin and myoD1, which is negative in CCAM.[12] Type IV CCAM may be associated with PPB.[13]

Prenatal, in utero, ultrasound helps early detection.[13] CCAM may lead to fetal hydrops and maternal polyhydramnios, antenatally with $100 \%$ mortality. Lung decompression, in utero, is done using thoracoamniotic shunts. 15-50\% CCAM shows significant reduction in size before birth. Complete postnatal resolution is rare, and apparent spontaneous "disappearance" of antenatally diagnosed lesions should be followed carefully, as nearly $50 \%$ of these cases subsequently require surgery.[9]

CXR, ultrasound, CT and MRI are used to identify location, extent and type of CCAM and to evaluate status of remaining normal lung, mediastinum, renal (renal agenesis), cardiac and gastrointestinal (diaphragmatic hernia and bowel atresia) systems. Doppler ultrasound helps to evaluate arterial and venous flow. The blood supply in CCAM is from pulmonary artery, in contrast to aorta in lung sequestration. ${ }^{[10]}$ Definitive diagnosis is by histopathology. Rarely, CCAM may harbor malignancy and bronchoalveolar carcinoma ${ }^{[14]}$ and embroynal rhabdomyosarcoma,[15] within CCAM, have been described in literature.

The definitive treatment of CCAM is surgery (lobectomy). Post lobectomy, the remaining lung grows and expands and total lung volume and pulmonary function tests return to normal.[15] Long term outcome is excellent for surgically managed asymptomatic patients. Affected children lead normal lives with only slight decrease in lung volume.

CONCLUSION: Early recognition and surgical treatment of CCAM is essential to prevent the consequences of recurrent pulmonary infections and the potential risk for malignant transformation and to allow children lead normal lives with apparently normal lung volume. Compressive effects of CCAM with mediastinal shift can cause hypoperfusion of heart and failure to thrive, secondary to compressed lung and decreased aeration. 


\section{REFERENCES:}

1. Chi'n KY, Tang MY. Congenital cystic adenomatoid malformation of one lobe of a lung with general anasarca. Arch Pathol Lab Med 1949; 48: 221-9.

2. Morotti RA, Cangiarella J, Gutierrez MC, Jagirdar J, Askin F, Singh G, et al. Congenital cystic adenomatoid malformation of the lung (CCAM): evaluation of the cellular components. Hum Pathol 1999; 30: 618-25.

3. Morelli L, Piscioli I, Licci S, Donato S, Catalucci A, Nonno FD. Pulmonary congenital cystic adenomatoid malformation, type I, presenting as a single cyst of the middle lobe in an adult: case report. Diagn Pathol 2007, 2: 17.

4. Mohta A, Kanojia RP, Bathla S, Khurana N. Cystic adenomatoid malformation of the lung: a diagnostic dilemma. Afr J Paediatr Surg 2009; 6: 112-3.

5. Cloutier MM, Schaeffer DA, Hight D. Congenital cystic adenomatoid malformation. Chest 1993; 103: 761-4.

6. Sindhwani G, Whig J, Gupta A, Rawat J. Tuberculosis in congenital adenomatoid malformation: a rare presentation. Lung India 2007; 24: 148-9.

7. Dahabreh J, Zisis C, Vassiliou M, Arnogiannaki N. Congenital cystic adenomatoid malformation in an adult presenting as lung abscess. Eur J Cardiothorac Surg 2000; 18: 720-3.

8. Stocker JT, Madewell JE, Drake RM. Congenital cystic adenomatoid malformation of the lung: classification and morphologic spectrum. Hum Pathol 1977; 8: 155-71.

9. Kuhn C, West WW, Craighead, Gibbs AR. Lungs. In: Damjanov I, Linder J, editors Anderson's Pathology. St. Louis: Mosby \& Co.; 1996: pp951-84.

10. Stocker JT. Congenital pulmonary airway malformation: a new name and an expanded classification of congenital cystic adenomatoid malformations of the lung. Histopathology 2002; 41: 424-31.

11. Hill DA, Jarzembowski JA, Priest JR, Williams G, Schoettler P, Dehner LP. Type I pleuropulmonary blastoma; pathology and biology study of 51 cases from the international pleuropulmonary blastoma registry. Am J Surg Pathol 2008; 32: 282-95.

12. Mac Sweeney F, Papagiannopoulos K, Goldstraw P, Sheppard MN, Corrin B, Nicholson AG. An assessment of the expanded classification of congenital cystic adenomatoid malformations and their relationship to malignant transformation. Am J Surg Pathol 2003; 27: 1139-46.

13. Singh M, Mitra S, Kumar L, Narang A, Rao KLN, Kakkar N. Congenital cystadenomatoid malformation of lung Indian Pediatr 2000;37:1269-74.

14. Kaslovsky RA, Purdy S, Dangman BC, McKenna BJ, Brien T, et al. Bronchoalveolar carcinoma in a child with congenital cystic adenomatoid malformation. Chest 1997; 112: 548-51.

15. D’Agostino S, Bonoldi E, Dante S, Meli S, Cappellari S, Musi L. Embryonal rhabdomyosarcoma of the lung arising in cystic adenomatoid malformation: a case report and review of literature. J Pediatr Surg 1997; 32: 1381-3. 
Figure 1: Chest radiograph showing left pleural effusion along with left upper and middle lobe consolidation, right mediastinal shift with heart compressed to right.

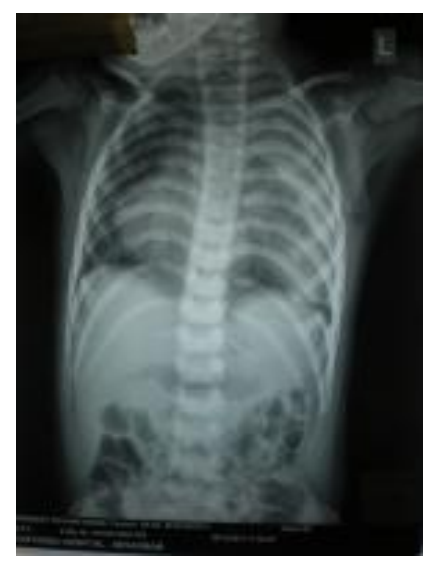

\section{Figure 1}

Figure 2: CT thorax showing multiple, non-enhancing, fluid density, cystic lesions with peripheral wall enhancement in apical and posterior segment of left upper lobe and apical, lateral basal and posterior basal segments of left lower lobe.

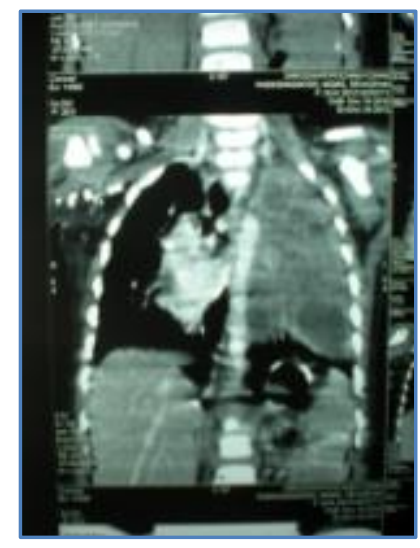

Figure 2

Figure 3: Intra-operatively large non aerated lung was visualized involving upper and middle lobe with normally aerated but compressed lower lobe.

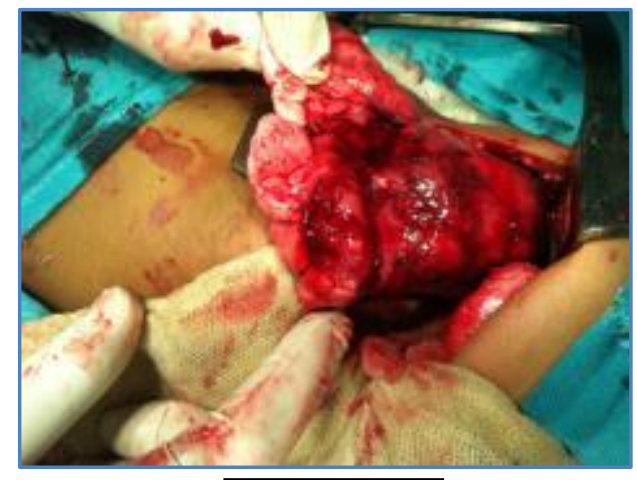

Figure 3 


\section{CASE REPORT}

Figure 4: Multiple pus filled cysts were seen during excision.

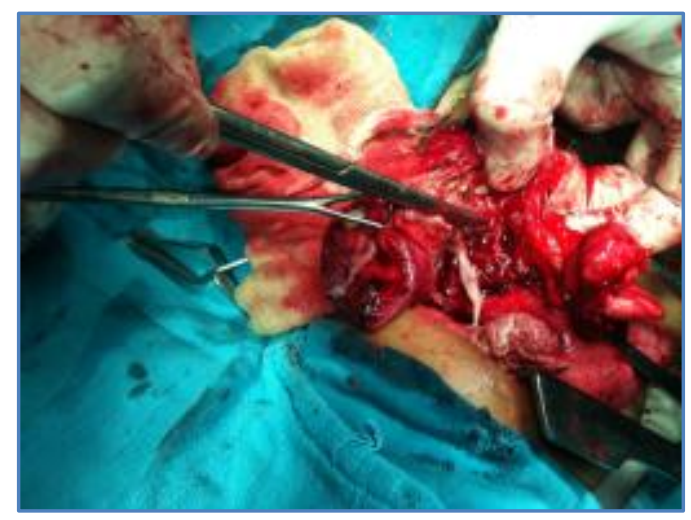

Figure 4

Figure 5: Expansion of normal lower lobe, after excision of CCAM.

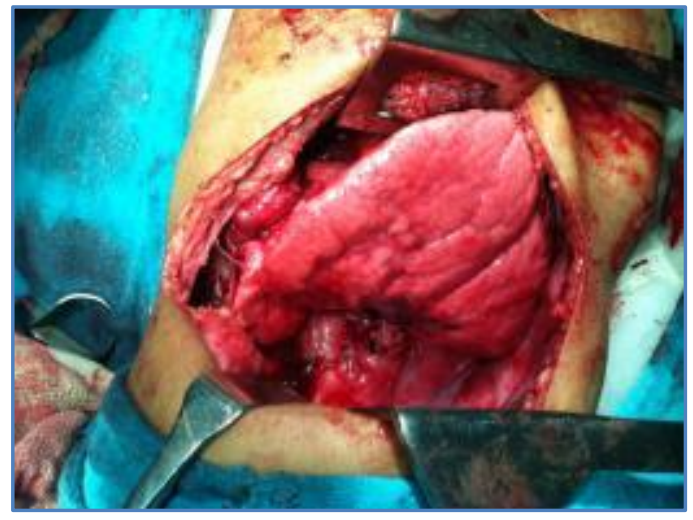

\section{Figure 5}

Figure 6: Gross examination showing $7.5 \times 5 \times 2.5 \mathrm{cms}$ CCAM with external surface well circumscribed, grayish white and cut surface showing cystic dilated spaces, filled with pus and hemorrhage.

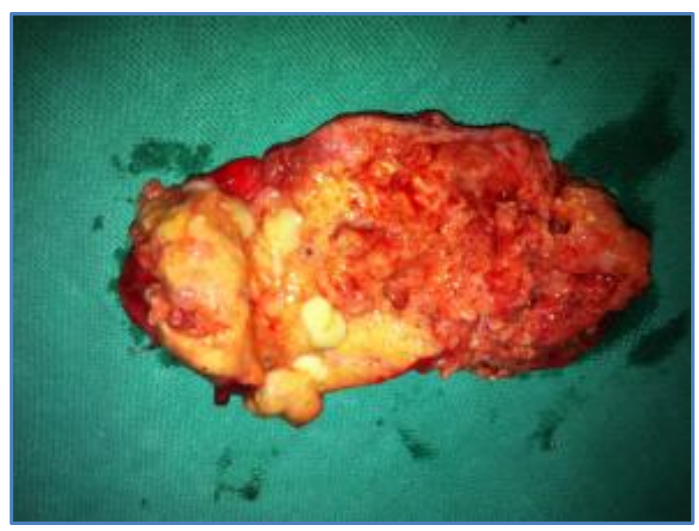

Figure 6 


\section{CASE REPORT}

Figure 7: Postoperative $\mathrm{X}$ ray showing expansion of normal lung with shift of heart to left.

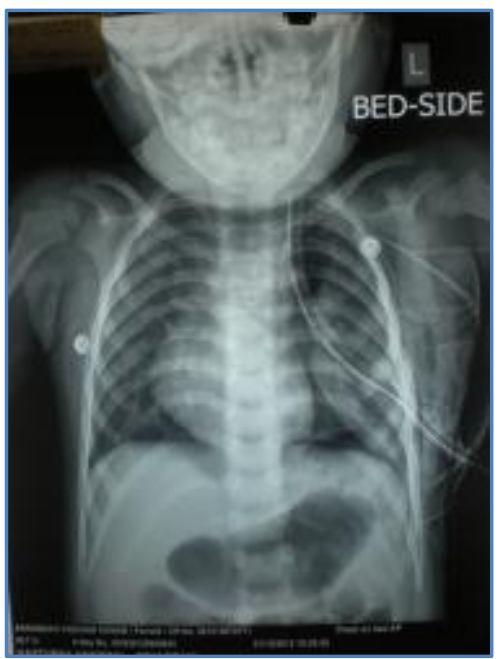

Figure 7

\section{AUTHORS:}

1. Mayuri A. Kamble

2. Anand P. Thawait

3. Ashok T. Kamble

\section{PARTICULARS OF CONTRIBUTORS:}

1. Assistant Professor, Department of Surgery, Govt. B J Medical College Pune Maharshtra.

2. Assistant Professor, Department of Surgery, Mahatma Gandhi Institute of Medical Sciences, Sewagram District, Wardha, Maharashtra.

3. Professor, Department of Surgery, Mahatma Gandhi Institute of Medical Sciences, Sewagram District, Wardha, Maharashtra.

\section{NAME ADDRESS EMAIL ID OF THE CORRESPONDING AUTHOR:}

Dr. Ashok T. Kamble,

Flat No. 1,

Old Subhedar Layout Extension, Ayodhya Nagar Post Office,

Nagpur-440024,

Maharashtra, India.

Email: anandthawait@yahoo.co.in

Date of Submission: 24/06/2014.

Date of Peer Review: 25/06/2014.

Date of Acceptance: 05/07/2014.

Date of Publishing: 11/07/2014. 